\title{
The pathological significance of Notch1 in oral squamous cell carcinoma
}

\author{
Ryoji Yoshida ${ }^{1,2}$, Masashi Nagata², Hideki Nakayama², Kanako Niimori-Kita' ${ }^{1}$, Wael Hassan¹,3, Takuji Tanaka ${ }^{4,5}$, \\ Masanori Shinohara ${ }^{2}$ and Takaaki Ito ${ }^{1}$
}

Notch signaling has been reported to be involved in several types of malignant tumors; however, the role and activation mechanism of Notch signaling in oral squamous cell carcinoma (OSCC) remains poorly characterized. The purpose of this study was to elucidate the pathological significance of Notch signaling and its activation mechanism in the development and progression of OSCC. In this study, we showed that the expression of Notch1 and intracellular Notch domain (NICD) are upregulated in OSCCS. In addition, Notch1 and NICD were found to be characteristically localized at the invasive tumor front. TNF- $\alpha$, a major inflammatory cytokine, significantly activated Notch signaling in vitro. In a clinicopathological analysis, Notch1 expression correlated with both the T-stage and the clinical stage. Furthermore, loss of Notch1 expression correlated with the inhibition of cell proliferation and TNF- $\alpha$-dependent invasiveness in an OSCC cell line. In addition, $\gamma$-secretase inhibitor (GSI) prevented cell proliferation and TNF- $\alpha$-dependent invasion of OSCC cells in vitro. These results indicate that altered expression of Notch1 is associated with increased cancer progression and that Notch1 regulates the steps involved in cell metastasis in OSCC. Moreover, inactivating Notch signaling with GSI could therefore be a useful approach for treating patients with OSCC.

Laboratory Investigation (2013) 93, 1068-1081; doi:10.1038/labinvest.2013.95; published online 12 August 2013

KEYWORDS: invasion; Notch signaling; oral squamous cell carcinoma; TNF- $\alpha$; proliferation

Oral cancer is one of the most common cancers, ${ }^{1}$ and the survival rate of patients with oral cancer has not improved despite improvements and innovations in diagnostic techniques and treatments. ${ }^{2}$ It is thought that most, if not all, cases of oral squamous cell carcinoma (OSCC) are preceded by a period during which the affected epithelium shows evidence of epithelial dysplasia, although this may not always be clinically apparent. ${ }^{3}$ Histological criteria to assess cellular and tissue changes (dysplasia) have been defined by the World Health Organization ${ }^{4}$ and are related to alterations in the kinetics of cellular proliferation and the maturation of the epithelium. ${ }^{5} \mathrm{~A}$ better understanding of the molecular mechanisms underlying the development of OSCC may add to the treatment and prognosis of this disease.

The Notch signaling pathway has an important role in cellular patterning and differentiation during development. ${ }^{6}$
Notch signaling has been highly conserved through the evolution from worm to man. Mammals have four Notch receptors (Notch1-4) that are transmembrane receptors harboring an extracellular domain responsible for the binding of their specific ligands and an intracellular domain involved in transcriptional regulation. Notch receptors can receive signals from neighboring cells that express transmembrane-type ligands such as Delta-like ligand and Jagged (JAG). ${ }^{7}$ Ligand binding to Notch receptors leads to the activation of common intracellular signaling pathways, which results in the cleavage of the intracellular Notch domain (NICD). NICD translocates into the nucleus and heterodimerizes with CSL/CBF-1/RBP-J $\kappa$. The CSL/CBF-1/RBP-J $\kappa-$ NICD complex is activated by the Mastermind family of coactivators and transactivates target genes such as mammalian hairly enhancer of split (Hes) and Hey family members. ${ }^{8}$

\footnotetext{
${ }^{1}$ Department of Pathology and Experimental Medicine, Graduate School of Medical Sciences, Kumamoto University, Kumamoto, Japan; ${ }^{2}$ Department of Oral and Maxillofacial Surgery, Graduate School of Medical Sciences, Kumamoto University, Kumamoto, Japan; ${ }^{3}$ Department of Pathology, Faculty of Medicine, Suez Canal University, Ismailia, Egypt; ${ }^{4}$ The Tohkai Cytopathology Institute: Cancer Research and Prevention (TCI-CaRP), Gifu, Japan and ${ }^{5}$ Department of Pathology, Kanazawa Medical University, Ishikawa, Japan

Correspondence: Professor T Ito, MD, DMSc, Department of Pathology and Experimental Medicine, Graduate School of Medical Sciences, Kumamoto University, Honjo 1-1-1, Chuo-ku, Kumamoto 860-8556, Japan.

E-mail: takaito@kumamoto-u.ac.jp

Received 17 April 2013; accepted 9 July 2013
} 
The association between Notchl signaling and tumorigenesis was first noted in a subset of T-cell acute lymphoblastic leukemia (T-ALL). ${ }^{9}$ The gain-of-function mutations in areas of Notch1 heterodimerization may partially account for the incidence of ALL cases exhibiting increased Notch pathway activity. Recent studies have also identified activated Notch1 mutations in chronic lymphocytic leukemia. ${ }^{10}$ The dysregulated expression of Notch receptors, ligands and targets is also observed in solid tumors, including lung, pancreatic, cervical and prostate carcinomas. ${ }^{11-14}$ High-level expressions of Notch1 and JAG1 are associated with poor prognoses in patients with breast cancer or metastasis of prostate cancer. ${ }^{15,16}$ On the other hand, there is growing evidence that Notch signaling activation may have growthsuppressive functions in other hematopoietic cells, hepatocytes, the pancreatic epithelium and skin. ${ }^{17-20}$

Several studies have indicated that upregulation of Notch signaling may contribute to the malignant phenotype in head and neck squamous cell carcinomas (HNSCCs), including those of the oral cavity. ${ }^{21,22}$ However, some researchers have shown that Notch signaling has a tumor suppressive role. ${ }^{23,24}$ To resolve the discrepancies between the reported roles of Notch signaling in OSCCs, the precise knowledge of the expression of Notch in normal and cancerous lesions of the oral cavity is crucial.

To better understand the role of the Notch pathway in oral carcinogenesis, we first examined immunohistochemical staining patterns of Notch1, NICD and JAG1 in normal epithelium, premalignant lesions (dysplasia) and cancer tissue of the oral cavity. We confirmed the presence of similar patterns using immunohistochemical staining in a rat carcinogenesis model. Next, we examined the expression of Notch signaling-related molecules in OSCC cell lines. Based on the results of the reinvestigation of the localization of Notch1 and NICD immunoreactions, we focused on the relationship between Notch 1 expression and tumor invasion, especially inflammation-related tumor invasiveness. To clarify the involvement of Notch1 in the proliferation and TNF- $\alpha$-dependent activation of tumor invasion, we used Notch1-specific small interfering RNA (siRNA) to knockdown the Notch1 gene in an OSCC cell line. Finally, we examined the effects of Notch pathway inhibition by the $\gamma$-secretase inhibitor (GSI), a pharmacological agent known to effectively block Notch activation, on the proliferation and TNF- $\alpha$-dependent invasiveness of OSCC cell lines.

\section{MATERIALS AND METHODS}

\section{Patients and Tissue Specimens}

Tissue samples of OSCC $(n=12)$, dysplasia $(n=36)$ and adjacent normal mucosa $(n=12)$ were obtained from 50 patients and used for the following studies. The samples were fixed with $10 \%$ formalin (fixation duration was up to 1 week) and embedded in paraffin. The tissues sections were stained with hematoxylin and eosin. A histological diagnosis of the samples was made according to the criteria of the World
Health Organization. ${ }^{4}$ Additional sections were used for immunohistochemical staining.

For the clinicopathologic analysis, primary oral cancer tissue samples were obtained from 54 patients with advanced OSCC treated at Kumamoto University Hospital between October 2003 and January 2009. All patients were preoperatively treated with chemoradiotherapy. Radiotherapy was administered at a daily dose of 2.0 Gy five times a week for 15 days. An oral fluorouracil anticancer agent, S-1, was concurrently administered at a dose of 80,100 or $120 \mathrm{mg}$ per day according to each patient's body surface area for 14 days after the initiation of radiotherapy. All tumors were staged according to the TNM classification of the UICC (2002), and the degree of differentiation was determined according to the grade classification of the WHO. The study followed the guidelines of the Ethics Committee of Kumamoto University. The nature and aims of the study were explained to all patients, who gave their informed consent for the research.

\section{Animals, Carcinogens and Tissue Specimens}

Rat lingual tissues containing normal, dysplastic and cancerous lesions were prepared as described previously. ${ }^{25}$ Briefly, male F344 rats were exposed to either control water or water-containing 4-nitroquinoline 1-oxide (4-NQO) for at least 28 weeks. Then, the rats were killed and lingual tissue specimens were obtained. A total of 15 paraffin sections (of normal epithelium, dysplastic tissue and tissue of invasive carcinoma, $n=5$ for each group) were used for immunohistochemical staining. Animals were handled in accordance with the animal care policy of Kanazawa Medical University.

\section{Immunohistochemical Staining and Evaluation}

Formalin-fixed, paraffin-embedded (FFPE) specimens were cut into $4-\mu \mathrm{m}$ sections and mounted on MAS-GP-coated slides (Matsunami Glass Ind., Osaka, Japan). After being deparaffinized and rehydrated, the sections were heated using an autoclave in $1 \mathrm{mM}$ EDTA and Tris/HCl buffer ( $\mathrm{pH} 9.0)$ (for Notch1) or $0.01 \mathrm{~mol} / \mathrm{l}$ citrate buffer ( $\mathrm{pH} \mathrm{7.0)}$ (for JAG1 and NICD) for antigen retrieval. The sections were incubated with $0.3 \% \mathrm{H}_{2} \mathrm{O}_{2}$ in absolute methanol for $30 \mathrm{~min}$ to block endogenous peroxidase activity. Then, the sections were incubated with Protein Block Serum Free Reagent (Dako, Glostrup, Denmark) for 15 min to block nonspecific staining. After the blocking step was completed, the sections were incubated with antibodies against Notch1 (D1E11; Cell Signaling Technology, Danvers, MA, USA), JAG1 (Epitomics, CA, USA) or NICD (Val1744 Rabbit mAb; Cell Signaling Technology) at $4{ }^{\circ} \mathrm{C}$ overnight. This was followed by sequential 60-min incubations with the secondary antibodies (En Vision + System-HRP-Labeled Polymer; Dako) and visualization with the Liquid $\mathrm{DAB}+$ Substrate Choromogen System (Dako). All slides were counterstained with hematoxylin for $30 \mathrm{~s}$ before being dehydrated and mounted. The results for Notch1 and JAG1 were considered positive when 
cells showed membranous positive staining, and the results for NICD were considered positive when cells displayed nuclear staining. Two independent observers interpreted the immunohistochemical data in a blinded manner. For each specimen, one score was assigned according to the percentage of positive cells: $<5 \%$ : 1 point; $6-35 \%$ : 2 points; $36-70 \%: 3$ points; and >71\%: 4 points, and another score was assigned according to the intensity of the staining, with negative staining equaling 1 point, weak staining equaling 2 points, moderate staining equaling 3 points and strong staining equaling 4 points. Notchland JAG1 expression scores were then calculated by multiplying the two scores described above. If the expression score was $\geq 4$, the tumor was considered to be positive.

\section{Cell Lines}

Human OSCC cell lines, namely, HSC-2, HSC-3, SAS, SCC-KN and Ca9-22 were kindly donated by the Department of Oral and Maxillofacial Surgery, Graduate School of Dental Science, Kyushu University and OSC-20, OSC-19 and HOC-313 were kindly donated by the Department of Oral and Maxillofacial Surgery, Kanazawa University Graduate School of Medical Science. All cell lines were cultured in Dulbecco's modified Eagle's medium (DMEM; GIBCO, Gland Island, NY, USA) with $10 \%$ fetal bovine serum (FBS). The cells were incubated at $37^{\circ} \mathrm{C}$ in $5 \% \mathrm{CO}_{2}$ and saturated humidity.

\section{Western Blotting}

Cells were lysed on ice in $150 \mathrm{mM} \mathrm{NaCl}, 1 \%$ Triton X-100, $0.5 \%$ sodium deoxycholate, $0.1 \%$ SDS, 1 mM EDTA- $2 \mathrm{Na}$ (pH 8.0), 1 mM EGTA (pH 7.5), $2.5 \mathrm{mM}$ sodium pyrophosphate, $1 \mathrm{mM} \beta$-glycerophosphate, $1 \mathrm{mM} \mathrm{Na}_{2} \mathrm{VO}_{4}, 1 \mathrm{mM}$ PMSF and $20 \mathrm{mM}$ Tris- $\mathrm{HCl}(\mathrm{pH}$ 7.5) containing a protease inhibitor cocktail (Roche Diagnostics, Basel, Switzerland). Protein concentrations were determined using the BCA assay (Bio-Rad Laboratories, Hercules, CA, USA). Samples were boiled with Laemmli buffer. Equal amounts of protein were electrophoresed on polyacrylamide gels containing $0.1 \%$ SDS, transferred to PVDF membranes (Millipore, Hamburg, Germany) and incubated with specific primary antibodies against Notch1 rabbit monoclonal antibodies (C44H11; Cell Signaling Technology), cleaved Notch1 (Val1744) rabbit monoclonal antibodies (D3B8; Cell Signaling Technology), Hes1 rabbit antibodies (a kind gift from Dr Sudo, Toray Corporation, Yokohama, Japan), ${ }^{26}$ Hes related with YRPW motif 1 (Hey1) rabbit polyclonal antibodies (ab22614; Abcam, Cambridge, UK), Akt (Cell Signaling Technology), phosphorylated Akt (Ser473) murine monoclonal antibodies (p-Akt; 587F11; Cell Signaling Technology), phosphorylated histone H3 (p-H3; Ser10; Millipore) and $\beta$-actin (AC-74; Sigma Aldrich, St Louis, MO, USA). Proteins of interest were detected with appropriate horseradish peroxidaseconjugated secondary antibodies and an enhanced chemiluminescence substrate (Amersham Pharmacia Biotech, Buckinghamshire, UK).

\section{RNA Isolation, RT-PCR and Quantitative Real-Time PCR} Total RNA was isolated using Trizol (Invitrogen, Carlsbad, CA, USA) according to the instructions provided by the manufacturer and reverse transcribed into cDNA using SuperscriptIII (Invitrogen) and oligo (dT). For qualitative PCR, the cDNA was amplified using PCR with specific primers. The following primers were used: Notch1 (forward: 5'-CGGGACATCACGGATCATATGGAC-3'; reverse: 5'-CCA CCCAGCGCCGCCATCTCGGGC-3'); JAG1 (forward: $5^{\prime}$-CG GGATTTGGTTAATGGTTATC-3'; reverse: 5'-ATAGTCACTG GCACGGTTGTAGCAC-3'); Hes1 (forward: $5^{\prime}$-TGGAAATG ACAGTGAAGCACCTC-3'; reverse: $5^{\prime}$-TCGTTCATGCACTC GCTGAAG-3'); Hey1 (forward: 5'-CGAGGTGGAGAAGGAG AGTG-3'; reverse: $5^{\prime}$-CTGGGTACCAGCCTTCTCAG-3'); and $\beta$-actin (forward: $5^{\prime}$-GTGGGGCGCCCCAGGCACCA-3'; reverse: $5^{\prime}$-CTCCTTAATGTCACGCACGATTTC- $3^{\prime}$ ). The PCR products were analyzed using agarose gel electrophoresis and visualized using staining with ethidium bromide.

For quantitative real-time PCR (qRT-PCR), each reaction mixture was diluted fivefold with DNase/RNase-free water (Invitrogen), and $4 \mu \mathrm{l}$ of each mixture were subjected to PCR. The reactions were run using THUNDERBIRD SYBR qPCR Mix (Toyobo, Osaka, Japan) on a Light Cycler 1.5 (Roche, Indianapolis, IN, USA). The comparative $\mathrm{Ct}(\Delta \Delta \mathrm{Ct})$ method was used to determine fold changes in expression using glyceraldehyde-3-phosphate dehydrogenase (GAPDH). Each sample was run in triplicate. The following primers were used: Snail (forward: 5'-TCGGAAGCCTAAACTACAGCGA-3'; reverse: $5^{\prime}$-AGATGAGCATTGGCAGCGAG-3'); Slug (forward: 5'-AAGCATTTCAACGCCTCCAAA-3'; reverse: 5'-GGATCTC TGGTTGTGGTATGACA-3'); Twist (forward: $5^{\prime}$-GTCCGCAG TCTTACGAGGAG-3'; reverse: 5'-GCTTGAGGGTCTGAATC TTGCT- $3^{\prime}$ ); and GAPDH (forward: $5^{\prime}$-TGTTGCCATCAATG ACCCCTT-3'; reverse: 5'-CTCCACGACGTACTCAGCG-3'). The cycling conditions were as follows: initial denaturation at $98^{\circ} \mathrm{C}$ for $5 \mathrm{~min}$, followed by 45 cycles at $98^{\circ} \mathrm{C}$ for $15 \mathrm{~s}, 60^{\circ} \mathrm{C}$ for $30 \mathrm{~s}$ and $72{ }^{\circ} \mathrm{C}$ for $60 \mathrm{~s}$. The experiments were performed in triplicate.

\section{Immunofluorescence Microscopy}

The cells were fixed in $4 \%$ paraformaldehyde in a phosphatebuffered saline (PBS) solution for $30 \mathrm{~min}$. After fixation was completed, the cells were centrifuged at 2500 r.p.m. for 10 to $15 \mathrm{~min}$. The supernatant was poured off and the cell pellets were embedded in paraffin blocks. Microtome was used to section the blocks of FFPE cells into $4-\mu$ m-thick sections. The sections were then transferred to glass slides. The slides were deparaffinized before being analyzed. After being blocked with Protein Block Serum-Free Reagent (Dako) for $30 \mathrm{~min}$, the primary antibodies were diluted in Dako Real ${ }^{\mathrm{TM}}$ Antibody Reagent (Dako). After being incubated for $24 \mathrm{~h}$ with the antibodies and subsequently washed with PBS three times ( $5 \mathrm{~min}$ each), the cells were incubated with the secondary antibodies (Alexa Fluor ${ }^{\circledR} 568$ donkey anti-goat IgG; Molecular Probes, Eugene, OR, USA) diluted in Dako Real ${ }^{\mathrm{TM}}$ 
Antibody Reagent (Dako). After being washed, the cells were counterstained with 4', 6-diamidino-2-phenylindole (Sigma Aldrich, St Louis, MO, USA) for 5 min, washed with PBS three times ( 5 min each), mounted in Gel Mount Aqueous Mounting Medium (Sigma Aldrich) and examined with a fluorescent microscope.

\section{Transfection with siRNA}

SAS cells were used in this experiment. Twenty-four hours before siRNA transfection was performed, the cells were diluted in fresh medium without antibiotics and transferred to $60-\mathrm{mm}$ dishes (Nunc, Waltham, MA, USA). The cells were grown and transfected with Notch1-specific siRNA and Stealth ${ }^{\mathrm{TM}}$ RNAi Universal negative control (Sthealth siRNA, $40 \mathrm{nM}$; Invitrogen) using Lipofectamine RNAi MAX (Invitrogen), as per the manufacturer's instructions. The sequences for siRNA were as follows: for Notchl, sense strand 5'-UCGCAUUGACCAUUCAACUGGUGG- ${ }^{\prime}$, antisense strand $5^{\prime}$-CCACCAGUUUGAAUGGUCAAU- $3^{\prime}$. The cells were harvested $48 \mathrm{~h}$ post-transfection for western blotting.

\section{GSI Treatment}

SAS cells were seeded $24 \mathrm{~h}$ before the treatment was started. Then, InSolution ${ }^{\mathrm{TM}}$ GSI (Calbiochem, Darmstadt, Germany) was added at a final concentration of 5 or $10 \mathrm{mM}$. An equal amount of dimethyl sulfoxide (DMSO; Wako, Osaka, Japan) was used as the control for GSI.

\section{Cell Proliferation Analysis}

Cell proliferation was determined using the cell proliferation reagent WST-8 (Cell Counting Kit-8; Dojindo, Kumamoto, Japan). Briefly, $2 \times 10^{3}$ cells were seeded into 96-well plates in $100 \mu$ l of the medium in quadruplicate for each condition. At 24 and $48 \mathrm{~h}$, WST- 8 reagent was added to each well at a 1:10 dilution and the plates were incubated for an additional 3 hours at $37^{\circ} \mathrm{C}$. Sample absorbance was measured at 690/ $480 \mathrm{~nm}$. Each experiment was performed in triplicate.

\section{Matrigel Cell Invasion Assay}

Cell invasion activity was measured with the BioCoat Matrigel Invasion Chamber (Becton Dickinson, Tokyo, Japan) according to the manufacturer's protocol. OSCC cells transfected with or without Notch1 siRNA were inoculated on the coated Matrigel of the culture inserts (upper chamber) at a density of $2 \times 10^{5}$ cells per $500 \mu \mathrm{l}$ of serum-free DMEM. TNF- $\alpha(5 \mathrm{ng} / \mathrm{ml}$; R\&D Systems, Abingdon, UK) was then added to the culture insert (upper chamber) and incubated for $24 \mathrm{~h}$ at $37^{\circ} \mathrm{C}$ and a $5 \% \mathrm{CO}_{2}$ atmosphere. At the end of the incubation, the cells on the upper surface of the filter were completely removed with cotton swabs. The invaded cells that remained on the lower surface of the filter were fixed with methanol and stained with Diff-Quick (Sysmex, Hyogo, Japan). The numbers of stained cells in five randomly selected microscopic fields $(\times 200)$ per filter were counted. The experiments were repeated at least three separate times to confirm reproducibility. In these experiments, the inserts harboring type 1 collagen-coated filter (CytoSelect ${ }^{\mathrm{TM}}$ 24-Well Cell Invasion Assay, Collagen I; Cell Biolabs, San Diego, CA, USA) were used in control experiment. Briefly, $2 \times 10^{5}$ cells per $300 \mu \mathrm{l}$ of serum-starved SAS cells were added to the upper polycarbonate membrane insert $(8-\mu \mathrm{m}$ pore size) of the cell migration assay kit in a 24 -well plate. Then, TNF- $\alpha(5 \mathrm{ng} / \mathrm{ml}$; R\&D Systems) was then added to the upper insert. In the lower well, $500 \mu \mathrm{l}$ DMEM with 10\% FBS was used as a chemoattractant. After $24 \mathrm{~h}$ of incubation, migratory cells were stained, photographed and quantitated by absorption at $560 \mathrm{~nm}$.By using two types of filters in our preliminary experiment, the behavior of cells in TNF- $\alpha$-treated condition was confirmed to be similar, regardless of the matrix used in the filter.

\section{Statistical Analysis}

The differences in mean values between two groups were statistically analyzed using Student's $t$-test or the MannWhitney $U$-test, whereas the differences in mean values between multiple groups were analyzed using one-way ANOVA with the Bonferroni/Dunn test. For the analysis of Notch1 and NICD expressions in the tissue specimens, the $\chi^{2}$-test was used to determine the association between Notch1 and NICD. Fisher's exact test was used when one or more cells had expected values $<5$. All $P$-values were based on two-tailed statistical analyses, and $P$-values $<0.05$ were considered to be statistically significant $\left({ }^{*} P<0.05\right.$ and $\left.{ }^{*} P<0.01\right)$. All statistical analyses were completed using the JMP 9 software program (SAS Institute, Cary, NC, USA).

\section{RESULTS}

\section{Immunohistochemical Staining Patterns Indicate that} Notch1 Signaling is Involved in the Formation of OSCC

To determine the association between the expression of Notch1 signaling-related molecules and oral carcinogenesis, an analysis of the expression of these molecules was conducted using immunohistochemical staining. Tissue specimens containing 60 oral lesions and adjacent normal mucosa from 50 patients with dysplasia or OSCC (as described in patients and tissue specimens) were evaluated for the expression of Notch1, NICD and JAG1. All examined specimens were scored according to the criteria described in Materials and Methods. In most of the normal oral mucosal tissues, the immunoreactions for Notch1 were scanty and confined nonspecific reactions were observed in the basal and parabasal compartments (Figure $1 \mathrm{aD}$ ). In the dysplastic tissues, the dysplastic cells showed immunoreactions for Notch1 that were weak or moderate in intensity, and the numbers of Notch1-positive cells were slightly increased (Figure $1 \mathrm{aE}$ ). In the cancerous tissues, the majority of OSCC cells showed strong immunoreactions for Notch1 (Figure 1aF). The staining patterns of Notch1 was membranous, whereas that of NICD was nuclear (Figures $1 \mathrm{aG}-\mathrm{I}$ ). The immunoreactions of NICD tended to increase in both 
a
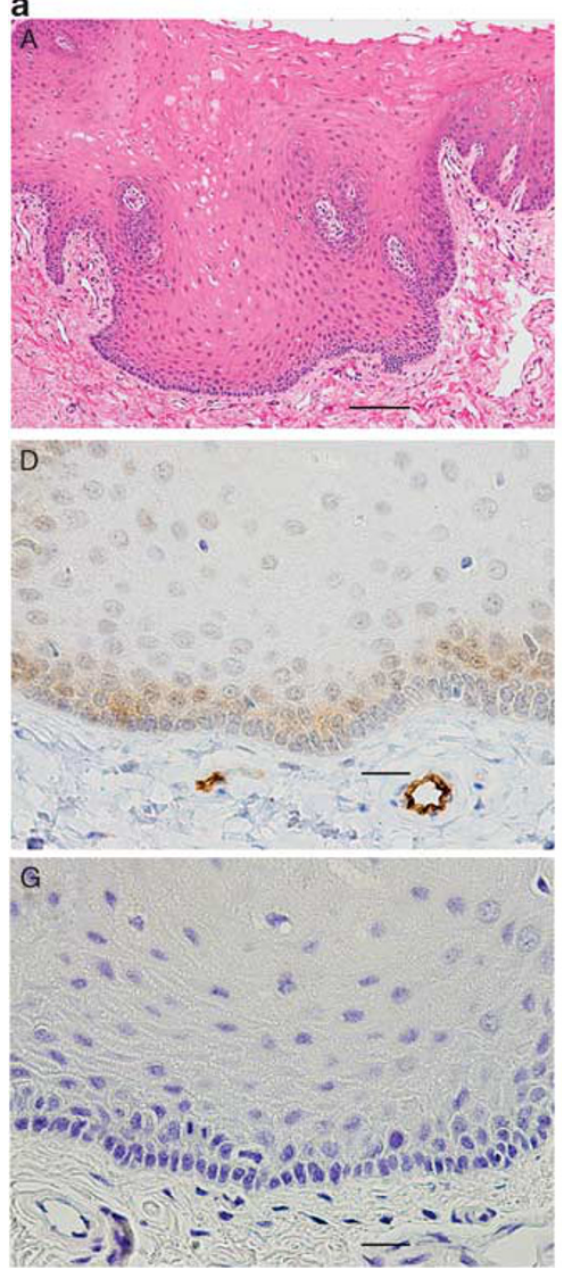
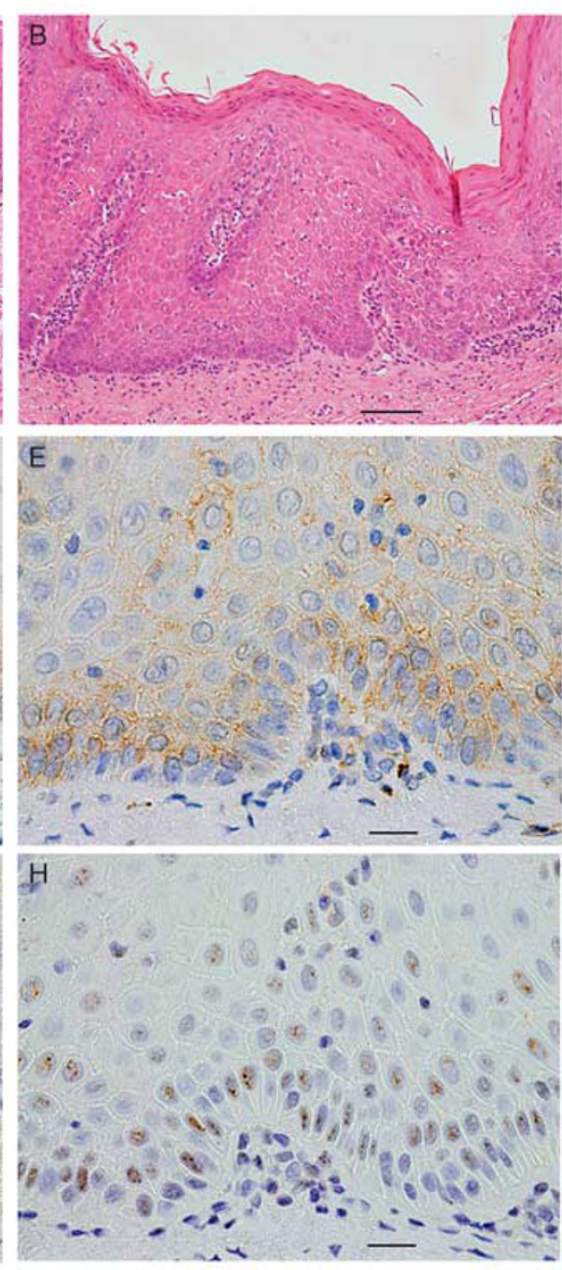
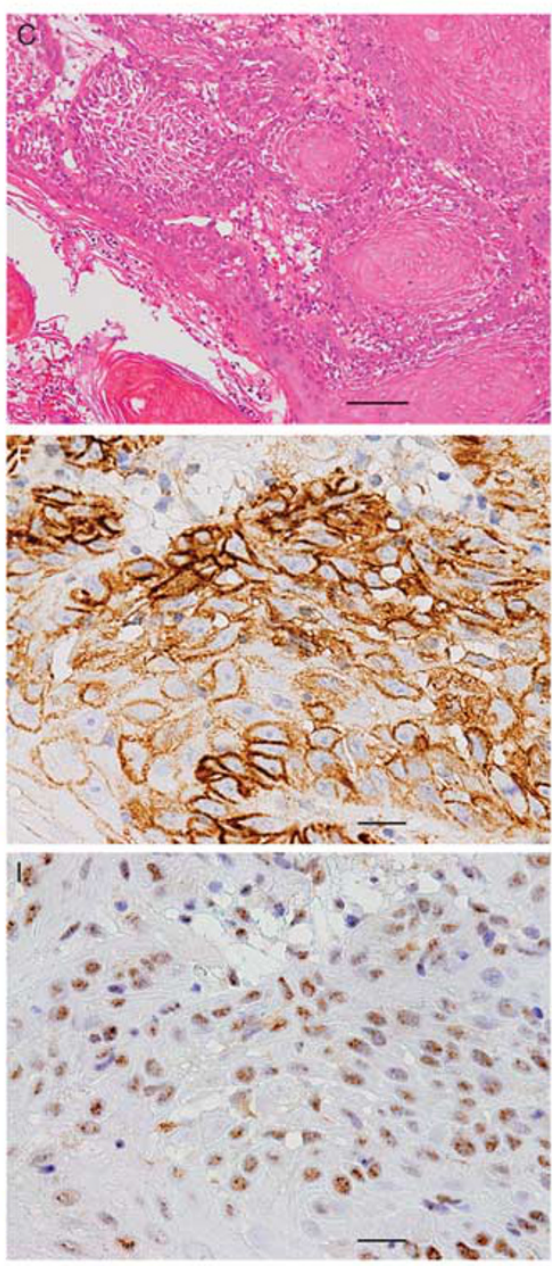

b

A
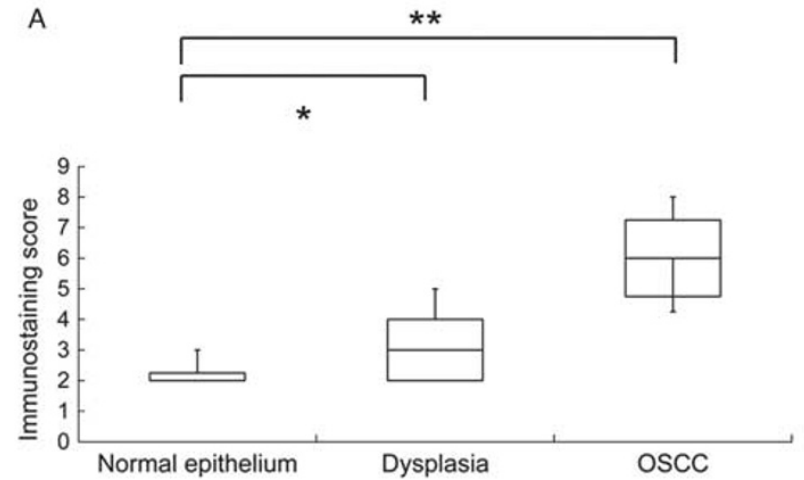

B
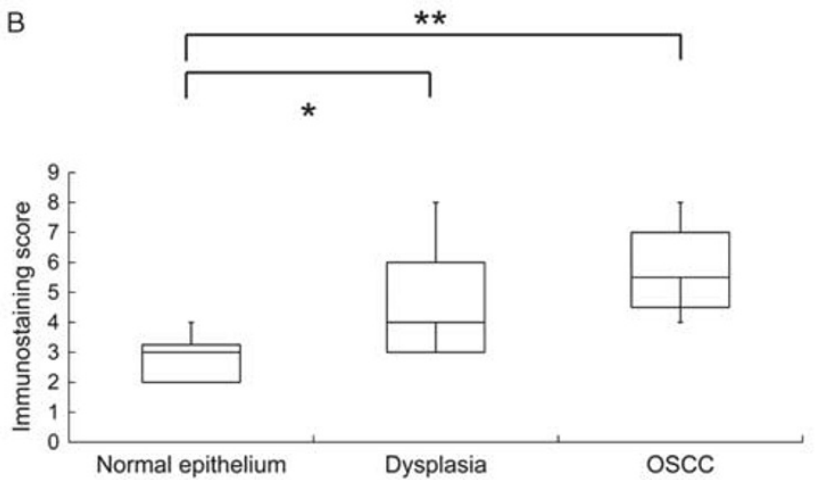

Figure 1 Immunohistochemical staining of Notch1 and its intracytoplasmic domain (NICD) in normal, dysplastic and cancerous tissues of oral mucosa. (a) Representative hematoxylin and eosin (H\&E) staining photomicrographs in: normal (A), dysplastic (B) and cancerous tissues (C) of oral mucosa. Original magnification, $\times 100$. Scale bar $=100 \mu \mathrm{m}$. (D-F) Representative immunohistochemical stainings of Notch1 at each pathological stage in highpower fields. Tissues were immunohistochemically stained using an antibody to Notch1. The membranous immunoreactions (brown) were regarded as positive for Notch1. Original magnification, $\times 400$. Scale bar $=20 \mu \mathrm{m}$. (G-I) Representative immunohistochemical stainings of NICD at each clinical stage in high-power fields. Tissues were immunohistochemically stained using an antibody to NICD. The nuclear immunoreactions (brown dots) were regarded as positive for NICD. Original magnification, $\times 400$. Scale bar $=20 \mu \mathrm{m}$. (b) (A) Graphs of Notch1 immunostaining scores. Immunostaining scores obtained from each pathological group were calculated and statistically analyzed. The mean Notch1 immunostaining score was the highest in the oral squamous cell carcinoma (OSCC) group. The $Y$ axis shows the mean values of the Notch1 immunostaining scores. (B) Graphs of NICD immunostaining scores. Immunostaining scores obtained from each pathological group were calculated and statistically analyzed. The mean NICD immunostaining score was the highest in the OSCC group. The $\mathrm{Y}$ axis shows the mean values of the NICD immunostaining scores. NS, no significance; ${ }^{*} P<0.05 ;{ }^{*} P<0.01$, analyzed by one-way analysis of variance (ANOVA) with the Bonferroni/Dunn test. 
Table 1 Relationship between immunoreactions of Notch1 and NICD

\begin{tabular}{lccc}
\hline & NICD positive & NICD negative & $P$-value \\
\hline Notch1 positive & 16 & 4 & $0.006^{* *}$ \\
Notch1 negative & 17 & 23 & \\
\hline
\end{tabular}

Fisher's exact test was used to examine the relationship between the Notch 1 and NICD expressions in the tissue specimens. ${ }^{* *} P<0.01$.

intensity and positivity from the normal tissues (Figure $1 \mathrm{aG}$ ) to the dysplastic tissues (Figure 1aH) to the OSCC tissues (Figure 1aI). The mean Notch1 immunostaining scores were $2.25 \pm 0.47$ in the normal epithelium $(n=12)$ and $3.06 \pm 0.85$ $(n=36)$ in the dysplastic tissues, and the OSCC tissues exhibited the highest expression (mean immunostaining score: $5.92 \pm 1.86(n=12)$; Figures 1bA; $P$-value $<0.01)$. The mean immunostaining score of NICD-positive cases were the lowest in the normal epithelium (mean immunostaining score: $2.92 \pm 0.79$ ), and increased expressions were observed in the dysplastic (mean immunostaining score: $4.43 \pm 1.78$ ) and OSCC tissues (mean immunostaining score: $5.50 \pm 1.78$; $P$-value $<0.01$; Figures $1 \mathrm{bB})$. This increase in the NICD expression correlated positively with the increase in the Notch1 expression, as determined by the $\chi^{2}$-test (Table 1; $P$-value $<0.01)$. Moreover, JAG1 showed similar results and exhibited the highest expression in the OSCC tissues (see Supplementary Figure S1).

To confirm the results obtained from the human specimens, we investigated the changes in Notch1 and NICD expressions in rat tongue tissues containing various pathological grades. In this experiment, normal epithelium $(n=5)$ and tissues of dysplasia $(n=5)$ and invasive OSCC $(n=5)$ were examined for Notchland NICD immunostaining. Similar to the results of the human specimens, the staining intensity and numbers of Notch1-positive cells increased in the tissues in the following order: normal epithelium, dysplastic tissues and cancerous tissues. The similar tendency was observed in immunostaining pattern of NICD (Figures 2a-i).

\section{Notch 1 and Related Molecules are Expressed in osCC Cell Lines}

To determine whether Notch1/NICD- and Notch1 signalingrelated molecules are expressed in cultured OSCC cell lines (HSC-2, HSC-3, SAS, Ca9-22, KN, OSC-20, OSC-19 and HOC-313), the cell lysates were analyzed using western blotting and RT-PCR. Using RT-PCR, mRNAs of Notch1and Notch1 signaling-related molecules were detected in almost all of the cell lines (Figure 3a). In immunofluorescence staining, Notch1, NICD, JAG1, Hes1 and Hey1 were also clearly detectable in in SAS cells (Figure 3b). In addition, the NICD expression was enhanced when the cells were treated with human recombinant JAG1 in our preliminary experiment (see Supplementary Figure S2). These results demonstrate that the genes and proteins of Notch1 and related molecules are expressed in OSCC-derived cells and signaling is activated in OSCC cell lines as a result of the nuclear expression of NICD.

Generally, NICD expressions reflect the activation status of Notch signaling. Based on the results of RT-PCR, western blotting, immunofluorescence staining and JAG1 treatment, SAS cells were regarded as one of the typical Notch1expressing OSCC cell lines. Therefore, SAS cells were used in following experiments in this study.

\section{Clinical Significance of Notch1 in OSCC Tissues}

Because increased Notch1 expression was observed in cancerous tissues and Notch1 signaling molecules were detected in the majority of OSCC cell lines, the clinical significance of Notch1 in human OSCC was examined using immunohistochemical staining. Tissues obtained from 54 patients with OSCC were evaluated for the expression of Notch1. The clinicopathologic details of the patients are shown in Table 2. Although no differences were observed in the expression status of Notch1 with respect to age, gender, primary tumor site or differentiation, the Notch1 expression was found to be positively correlated with T-stage and clinical stage $(P<0.05)$, as determined by the $\chi^{2}$-test. These results indicate that increased expression of Notch1 may correlate with OSCC progression.

\section{Notch1 Knockdown Inhibits the Proliferation of OSCC Cells}

To determine whether Notch1 expression affects the growth of OSCC cells, we examined the proliferation of SAS cells after treatment with Notch1 siRNA. The Notch1 siRNAtreated SAS cells exhibited a significant reduction in cell proliferation compared with the cells treated with negative control siRNA (Figure 4a; $P$-value $<0.05$ ). A microscopic examination confirmed that the number of cells was markedly decreased (Figure 4b). Based on the results of Notch1 knockdown experiments, we explored the possibility of alteration in signal-transduction pathway, such as Akt, MAPK and Stat3 pathway by using western blotting analysis. In addition, we also confirmed the reduction of proliferation activity by using $\mathrm{p}-\mathrm{H} 3$, one of the mitosis-associated molecules. Western blotting showed that the expressions of Notch1, NICD, Hes1 and p-H3, a mitosis-associated marker, were significantly reduced under Notch1 siRNAtransfected conditions. Moreover, a reduction in the level of p-Akt was observed under the same conditions (Figure 4c), although no remarkable changes in the levels of MAPK or Stat3 occurred (data not shown). From these results, we concluded that Notch1 has an important role, and Akt signaling could be involved in the proliferation of cultured OSCC cells. 


\section{Normal}

epithelium
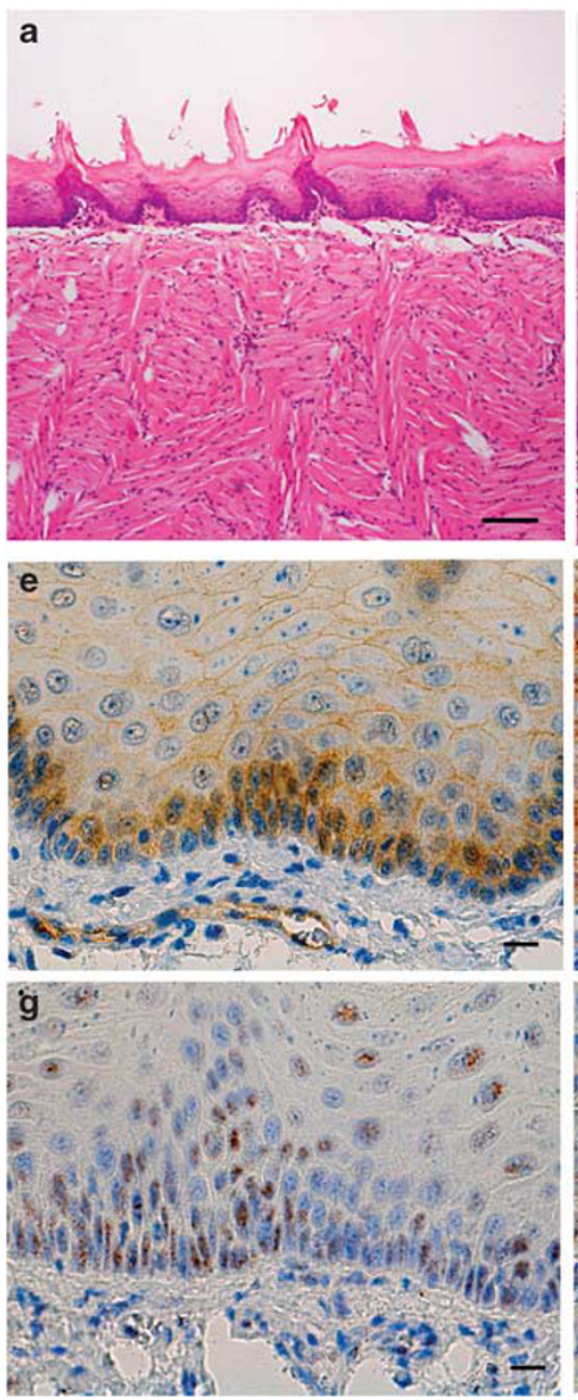

Dysplasia
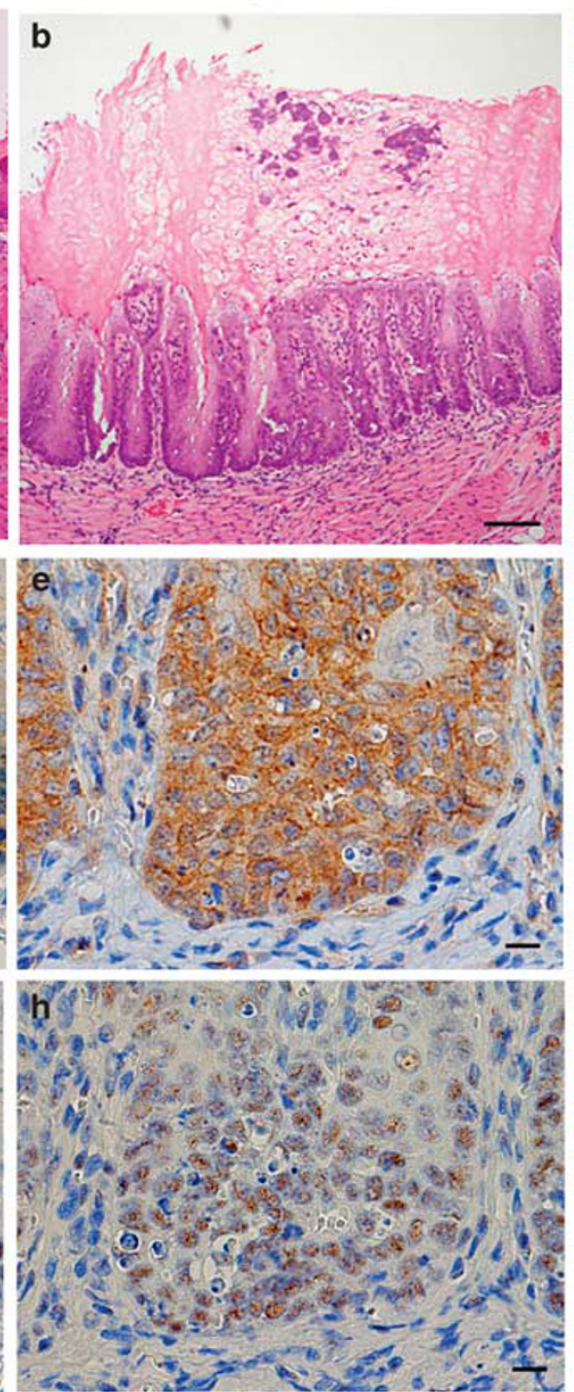

OSCC
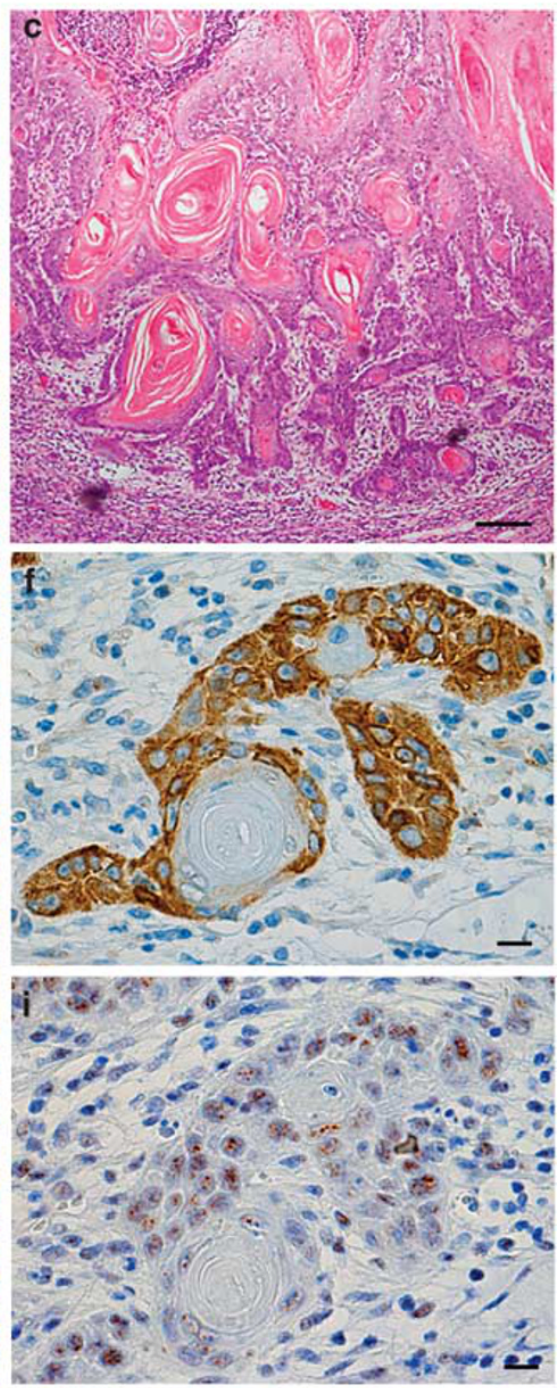

Figure 2 An immunohistochemical analysis of Notch1 in a rat carcinogenesis model. Representative hematoxylin and eosin (H\&E) staining photomicrographs of normal (a), dysplastic (b) and cancerous tissues (c) of the tongue obtained from rats used in a rat carcinogenesis model. Original magnification, $\times 100$. Scale bar $=100 \mu \mathrm{m}$. (d-f) Representative immunohistochemical stainings of Notch1 at each pathological grade in high-power fields. Tissues obtained from rats used in a rat carcinogenesis model were immunohistochemically stained using an antibody to Notch1. The membranous immunoreactions (brown) were regarded as positive for Notch1. Original magnification, $\times 400$. Scale bar $=20 \mu \mathrm{m}$. (g-i) Representative immunoreactions of Notch1 and intracellular Notch domain (NICD) in high-power fields. Tissues obtained from rats used in a rat carcinogenesis model were immunohistochemically stained using an antibody to NICD. The nuclear immunoreactions (brown dots) were regarded as positive for NICD. In the cancerous tissues, a majority of oral squamous cell carcinoma (OSCC) cells showed strong immunoreactions for NICD. Original magnification, $\times 400$. Scale bar $=20 \mu \mathrm{m}$.

\section{TNF $\alpha$-Dependent OSCC Cell Invasiveness}

To determine the significance of Notch1 expression other than proliferation, we further analyzed the expression pattern of Notch1 in the histological samples. In the OSCC specimens, Notch1 was primarily expressed in the cells at the epithelial-stromal interface (Supplementary Figure S3A). Furthermore, NICD was strongly expressed in the cells at the invasive tumor front (Supplementary Figure S3B).
Based on the localizations of Notch1 and NICD observed in the histological analysis, we hypothesized that Notch1 signaling could be involved in the invasiveness of OSCC cells. Therefore, a Matrigel invasion assay was completed to assess whether the Notch1 expression affects the invasiveness of OSCC cells in vitro. In this experiment, TNF- $\alpha$, a well-known accelerator of tumor invasion, was used. TNF- $\alpha$ has been reported to show an increased expression in OSCC specimens ${ }^{27}$ and promote S2 cleavage (resulting in NICD 
a

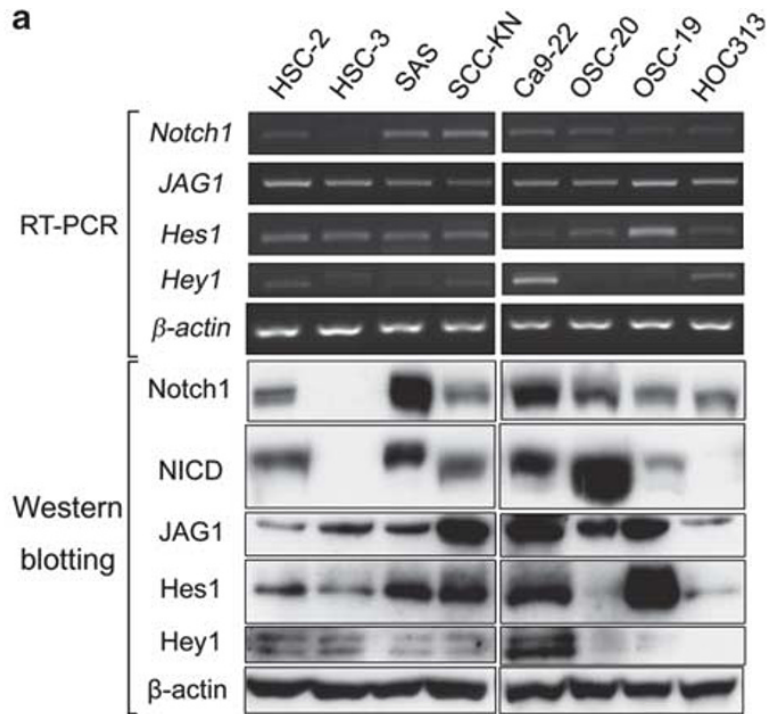

b

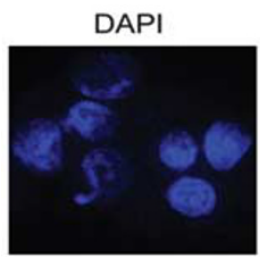

DAPI

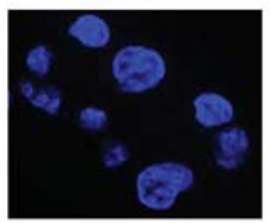

Notch 1

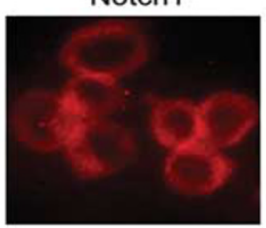

NICD

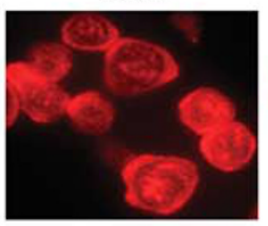

DAPI

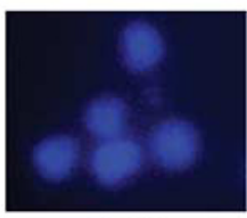

DAPI

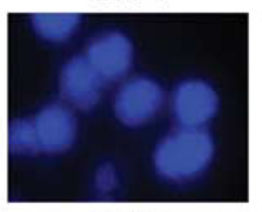

DAPI

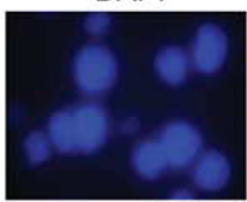

Hes 1

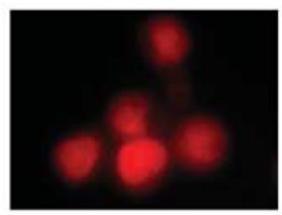

Hey1

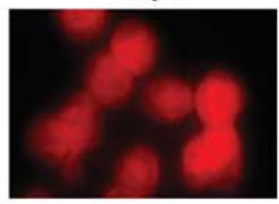

JAG1

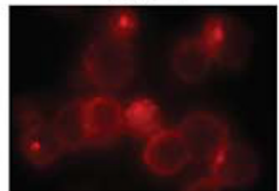

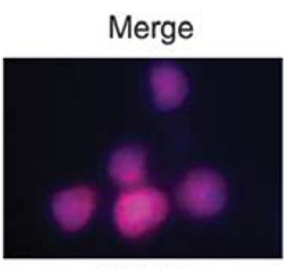

Merge

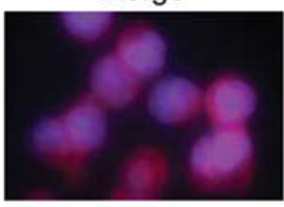

Merge

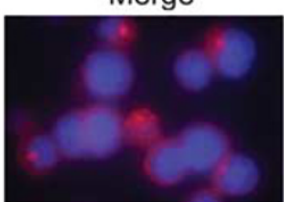

Figure 3 The mRNA and protein expressions of Notch1-related molecules in oral squamous cell carcinoma (OSCC) cell lines. (a) The mRNA (top panel) and protein (bottom panel) expressions of Notch1- and Notch1 signaling-related molecules in OSCC cell lines. OSCC cell lines cultured in the same conditions were harvested and supplied for real-time (RT)-PCR and western blotting. The mRNAs of Notch1- and Notch1 signaling-related molecules were found to be expressed in a majority of OSCC cell lines in RT-PCR. The Notch1 and Notch1 and intracellular Notch domain (NICD) expressions were clearly detectable in 9 of 10 cell lines using western blotting, and the other Notch1-related proteins were also similarly detected. (b) Immunofluorescent staining of Notch1, NICD, Jagged (JAG)1, hairly enhancer of split (Hes)1 and Hes related with YRPW motif (Hey1) in SAS cells. Each protein was detected using specific antibodies. The signals of all molecules (Alexa Fluor ${ }^{\mathbb{B}} 568$, red) were clearly detectable in the membranes or nuclei $\left(4^{\prime}, 6\right.$-diamidino-2-phenylindole (DAPI), blue) of SAS cells. Original magnification, $\times 400$.

production) via TACE maturation in Notch signaling. ${ }^{28-30}$ As shown in Figure 5, NICD cleavages were observed in a TNF- $\alpha$ concentration-dependent manner. In addition, NICD cleavage was inhibited by GSI treatment. Our results indicate the existence of activation mechanisms of Notch signaling by TNF- $\alpha$, and the potential utility of GSI for Notch signaling activation by TNF- $\alpha$. Indeed, in the control siRNA-transfected SAS cells, TNF- $\alpha$ markedly activated the invasive properties of the cells (Figures $6 \mathrm{a}$ and $\mathrm{b}$ ). The activation of tumor cell invasion was observed in the experiment using type 1 collagen-coated filter (Supplementary Figure 4S) and also in the experiment using Matrigel-coated filter. Therefore, in the following experiments, we used SAS cells treated with TNF- $\alpha$ in the Matrigel as a control for the experiments of Notch1 inhibition. In contrast, TNF- $\alpha$-dependent activation of tumor invasion was significantly inhibited under Notch1 knockdown conditions (Figures $6 c$ and d). To identify the mechanism underlying this phenomenon, we explored changes in related molecules using western blotting and quantitative real-time PCR. No significant changes were 
Table 2 Clinical significance of Notch 1 in OSCC tissues

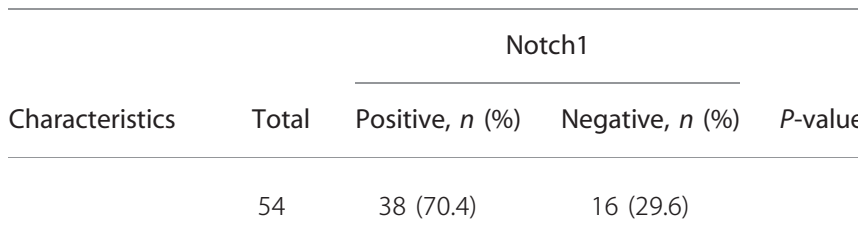

$\begin{array}{cccc}\text { Age (years) } & & & \\ \text { Median } & 70.5 & 70.7 & 70.1 \\ \text { Range } & 51-87 & 51-86 & 56-87 \\ \leq 65 & 18 & 12(66.7 \%) & 6(33.3 \%) \\ >65 & 36 & 26(72.2 \%) & 10(27.8 \%)\end{array}$

Gender

$\begin{array}{lllr}\text { Male } & 31 & 21(67.7 \%) & 10(32.3 \%) \\ \text { Female } & 23 & 17(73.9 \%) & 6(26.1 \%)\end{array}$

Primary site

Tongue

Mandible

Maxilla

Oral floor

Buccal mucosa

\section{3}

$10(76.9 \%)$

$3(23.1 \%)$

0.262

$6(60.0 \%)$

$4(40.0 \%)$

$6(50.0 \%)$

$6(50.0 \%)$

$7(77.8 \%)$

$2(22.2 \%)$

$1(10.0 \%)$

\section{T-stage}

$\mathrm{T} 1, \mathrm{~T} 2$

T3

$\mathrm{T} 4$

$12(63.2 \%)$

$17(94.4 \%)$

$7(36.8 \%)$

$1(5.6 \%)$

9 (52.9\%)

$8(47.1 \%)$

Nodal stage

$$
\leq 1
$$

$>2 \mathrm{a}$

Clinical stage

॥

III

IV

$21(67.7 \%)$

$10(32.3 \%)$

0.077

$2(10.5 \%)$

$3(75.0 \%)$

$0.005^{* *}$

1 (5.3\%)

$18(94.7 \%)$

12 (38.7\%)

Differentiation

$\begin{array}{lllrl}\text { Well } & 40 & 28(70.0 \%) & 12(30.0 \%) & 0.920 \\ \text { Moderate } & 14 & 10(71.4 \%) & 4(28.6 \%) & \end{array}$

The $\chi^{2}$-test was used to examine the relationship between the Notch1 expression and the clinicopathologic factors. ${ }^{*} P<0.05 ;{ }^{*} P<0.01$.

Fisher's exact test was used when one or more cells had expected values $<5$.

observed in the Stat3, MAPK or Akt pathways or in the expressions of matrix metalloproteinase (MMP)-2 or -9 (data not shown). However, mRNAs of Slug and Twist, critical transcriptional factors that control cell invasion, ${ }^{31}$ were affected by TNF- $\alpha$ treatment and decreased significantly under Notch1 knockdown conditions (see Supplementary Figures S5A-C). These results suggest that Notch1 may contribute in part to TNF- $\alpha$-dependent OSCC cell invasion via the transcriptional regulation of Slug and Twist.

\section{GSI Inhibits the Proliferation, Migration and Invasion of OSCC Cells}

To test the possible application of GSI in the treatment of OSCC, SAS cells were treated with GSI or a control vehicle (DMSO) and cell proliferation, migration and invasiveness were assessed. As shown in Figure 7a, GSI significantly inhibited cell proliferation in a dose-dependent manner $(P<0.05)$. Using western blotting, decreased expressions of NICD, Hes1, p-H3 and p-Akt were confirmed. Furthermore, the number of invaded cells enhanced by TNF- $\alpha$ was significantly decreased under the GSI treatment conditions (Figure $7 \mathrm{c} ; P$-value $<0.01$ ). These results suggest that GSI has a potential for clinical use in OSCC treatment.

\section{DISCUSSION}

Notch1 and its signaling have been examined in various types of cancer. Although the oncogenic role of Notch signaling in T-ALL is well established, ${ }^{32}$ a common theme for the role of Notch signaling in tumorigenesis remains elusive. In many types of solid tumor, including cancers of the lung, ${ }^{11}$ breast, ${ }^{16}$ pancreas ${ }^{13}$ and prostate. ${ }^{14}$ Notch1 signaling therefore seems to have a crucial role. Notch1 signaling also appears to have tumor suppressor roles in murine keratinocytes ${ }^{20}$ human pancreatic ${ }^{19}$ and hepatocellular carcinomas ${ }^{18}$ and small-cell lung cancer. ${ }^{33}$ Taken together, these observations indicate that aberrant activation of the Notch1 pathway has various roles in solid tumors. Moreover, the cellular reactions and outcomes of the overexpression of Notch1 activity are highly dependent on contextual cues such as interactions with the tumor microenvironment and crosstalk with other signaling pathways. Our present report provides an extensive evaluation of Notch1 expression in human OSCC tissues and the effects of Notch1 expression in OSCC cell lines.

Strong Notch1 expression was seen in the cell membrane of oral cancer cells in our present study, whereas a weak and limited expression was observed in the basal layer in normal tissues. In previous studies, the overexpression of Notch 1 and its ligands has been observed in OSCC specimens. ${ }^{34,35}$ However, a recent study demonstrated opposite results to this study. The study of Sakamoto et al ${ }^{24}$ showed similar Notch1 expression to that observed in our study in normal tissues, whereas their results for dysplastic and cancerous tissues were different, and Notch1 was downregulated in the neoplastic lesions.Although the antibodies against Notch1 and staining method used in our study were different from those used by Sakamoto et al, ${ }^{24}$ our immunohistochemical staining results showed clear and specific membranous 


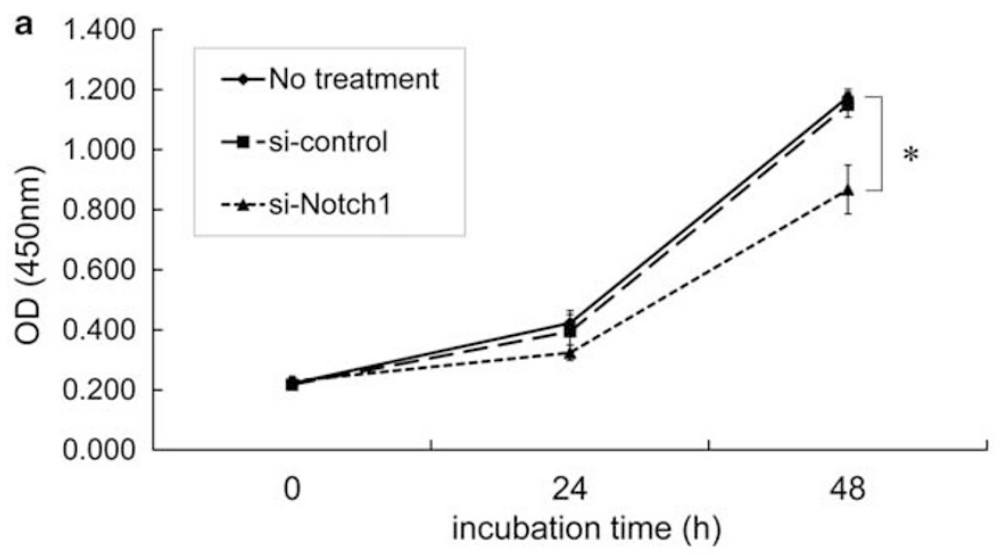

b

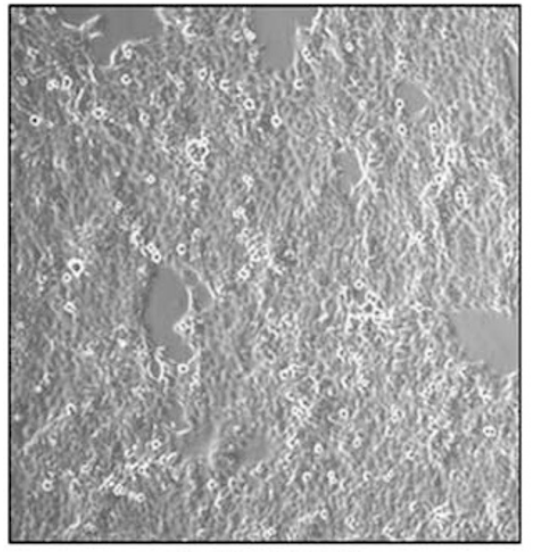

No treatment

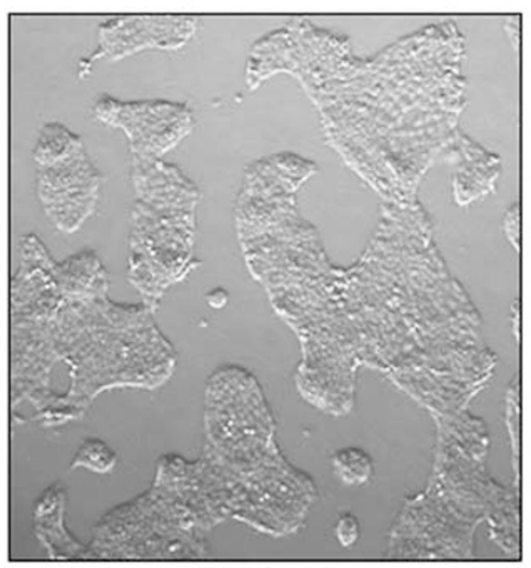

si-Notch1

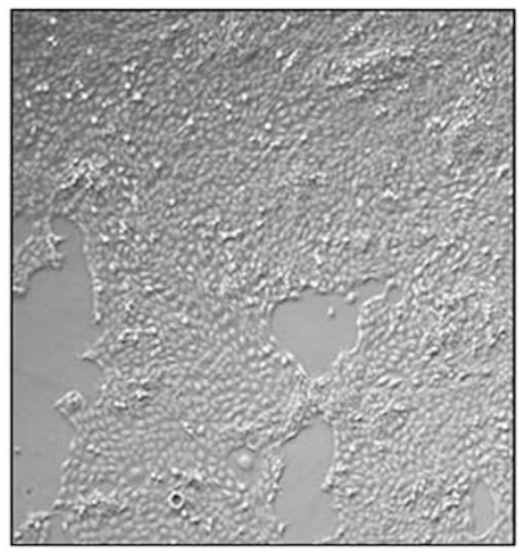

si-control
C

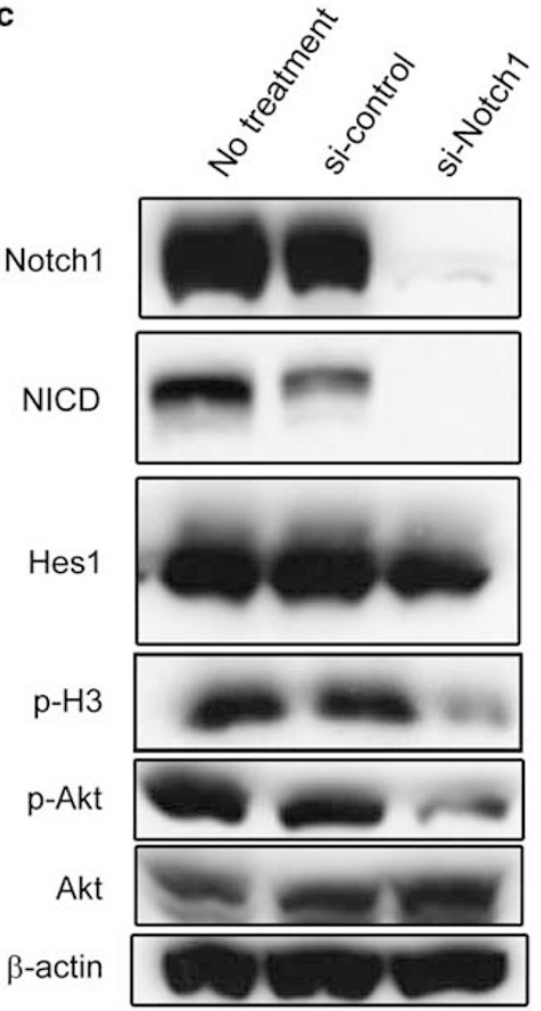

Figure 4 Effects of Notch1 small interfering RNA (siRNA) on the proliferation of SAS cells. (a) SAS cells were transfected with either control or Notch1-specific siRNA for the indicated periods and then examined for viability using a WST assay. Notch1 siRNA-treated SAS cells exhibited significant reductions in cell proliferation compared with the cells treated with negative control siRNA. The $Y$ axis shows the changes in absorbance at $450 \mathrm{~nm}$; bars \pm s.d. of three individual experiments. ${ }^{*} P<0.05$, analyzed by Student's $t$-test. (b) Images of SAS cells through the microscope under each condition. The number of cells was significantly decreased under Notch1-specific siRNA-treated conditions. Original magnification, $\times 100$. (c) Western blotting of Notch1 signaling-related proteins $48 \mathrm{~h}$ after transfection. Note the decreased expressions of Notch1, Notch1 and intracellular Notch domain (NICD), phosphorylated histone $\mathrm{H} 3(\mathrm{p}-\mathrm{H} 3)$ and phosphorylated AKT ( $\mathrm{p}-\mathrm{AKT})$ in the Notch1 siRNA-treated cells. The expression of $\beta$-actin was used as an internal control. The experiment was performed in triplicate. OD, optical density; Hes, hairly enhancer of split.

staining. In our study, NICD was similarly detected by immunohistochemistry in Notch1-positive cells, which supports that our Notch1 immunohistochemical results were reliable. Moreover, the present study demonstrated that many human OSCC lines had Notch1 protein and mRNA, which also supports that many surgically resected OSCC tissues are 
positively immunostained for Notchl. To strengthen our immunohistochemical study furthermore, we reinvestigated Notch1 expression in a rat carcinogenesis model useful for monitoring cancer-progression-related molecules. In the sequential analysis model of tongue carcinogenesis, the Notch1 expression exhibited the same tendency as that observed in the human tissue specimens. These results encouraged us to conclude that Notch1 overly accumulates or overexpresses and may have certain roles in the late stage of carcinogenesis and OSCC.

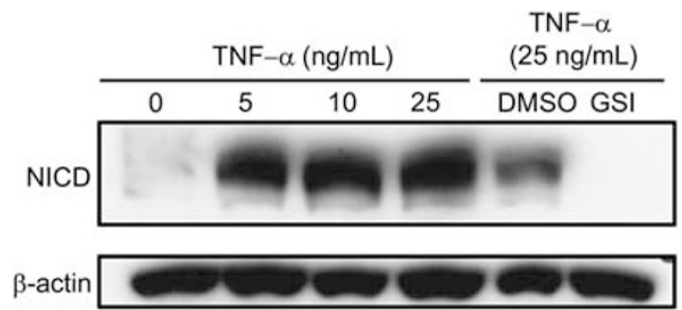

Figure 5 Effect of tumor necrosis factor (TNF)- $\alpha$ on Notch1 and intracellular Notch domain (NICD) cleavage in SAS cells. SAS cells were incubated with various concentrations of TNF- $\alpha$ alone or with dimethyl sulfoxide (DMSO) and $\gamma$-secretase inhibitor (GSI) for $24 \mathrm{~h}$, and then examined for NICD cleavage by western blot.

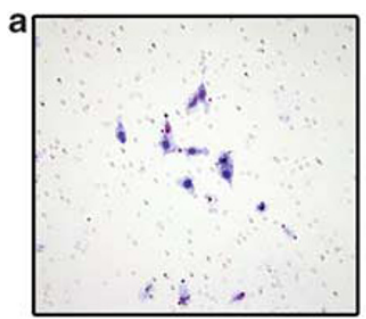

No treatment

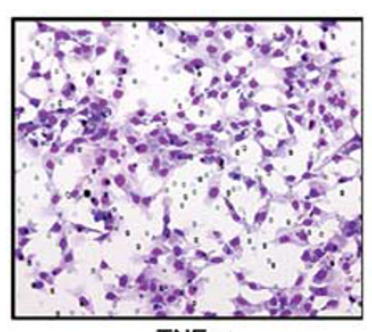

TNF- $\alpha$

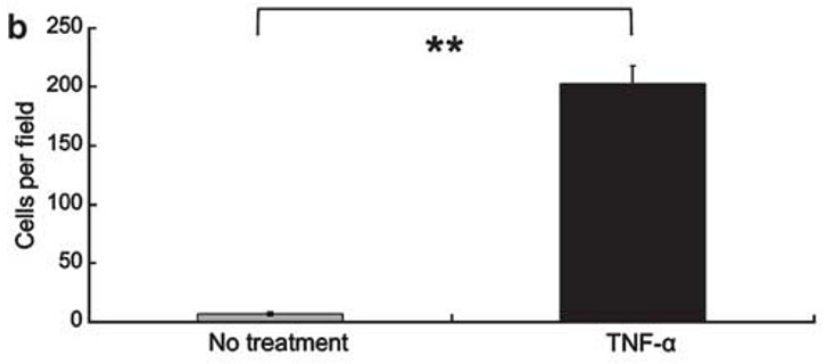

In our clinicopathological analysis, a high level of Notch1 expression was found to be correlated with both T-stage and clinical stage in patients with OSCC. Although a statistical correlation was not observed, an increasing percentage of patients with Notch1-positive cancers showed advanced Nodal status. These results indicate that Notch1 has a potential role in OSCC progression. In addition, similar to our present study, two reports have described the clinical significance of Notch1 expression in HNSCCs, including OSCC. ${ }^{36,37}$ Therefore, we concluded that Notch 1 may have an important role in OSCC progression.

Based on the histological findings observed in the human and rat OSCC samples, we hypothesized that Notch1 regulates the proliferation and invasiveness of OSCC cells. This was confirmed in vitro. First, we examined the expressions of Notch1, its related molecules and NICD, which indicates the activation of Notch1 signaling, in a panel of OSCC cell lines. Second, we investigated whether the Notch1 expression affects the proliferation of cultured OSCC cells using Notch1specific siRNA and a WST assay, as the importance of the Notch1 expression for cell proliferation is well known and has been previously examined. ${ }^{38-40}$ Most of OSCC cell lines expressed Notch1 signaling molecules and NICD, and Notch1 knockdown significantly inhibited cell proliferation

c
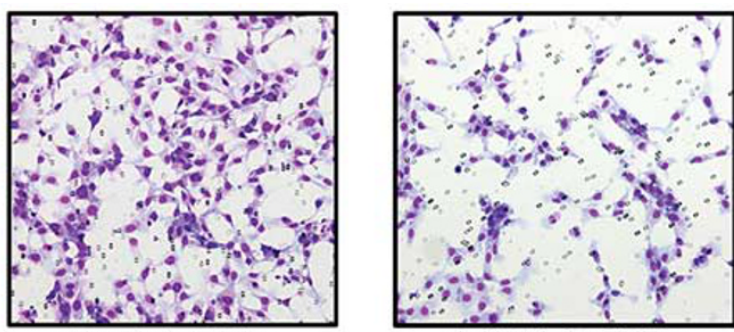
si-control + TNF- $\alpha$

si- Notch $1+$ TNF- $\alpha$

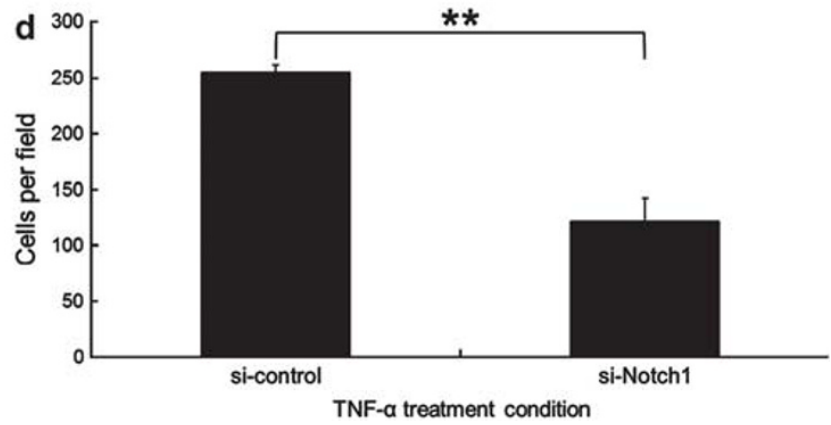

Figure 6 Effects of Notch1 small interfering RNA (siRNA) on SAS cell invasion. (a, b) The effects of tumor necrosis factor (TNF- $\alpha$ ) treatment on SAS cell invasion. SAS cells were incubated with either control or Notch1-specific siRNA for $24 \mathrm{~h}$ in the presence of TNF- $\alpha$. The numbers of invaded cells obtained from three independent experiments were counted and statistically analyzed. The photos are representative fields of invasive cells on the membranes. TNF- $\alpha$ markedly activated the invasive properties of the cells. Original magnification, $\times 100$. The bar graphs represent the average numbers of cells on the underside of the membranes. The $Y$ axis shows the numbers of cells invading the underside of the membranes. Mean \pm s.d. of three independent experiments. ${ }^{*} P<0.01$, analyzed by Student's $t$-test. (c, d) The effects of Notch1 siRNA on TNF- $\alpha$-dependent SAS cell invasion. The photos are representative fields of invasive cells on the membranes. TNF- $\alpha$-dependent activation of tumor invasion was significantly inhibited under Notch1 knockdown conditions. Original magnification, $\times 100$. The bar graphs represent the average numbers of cells on the underside of the membranes. The $Y$ axis shows the numbers of cells invading the underside of the membranes. Mean \pm s.d. of three independent experiments. ${ }^{*} P<0.01$, analyzed by Student's $t$-test. 


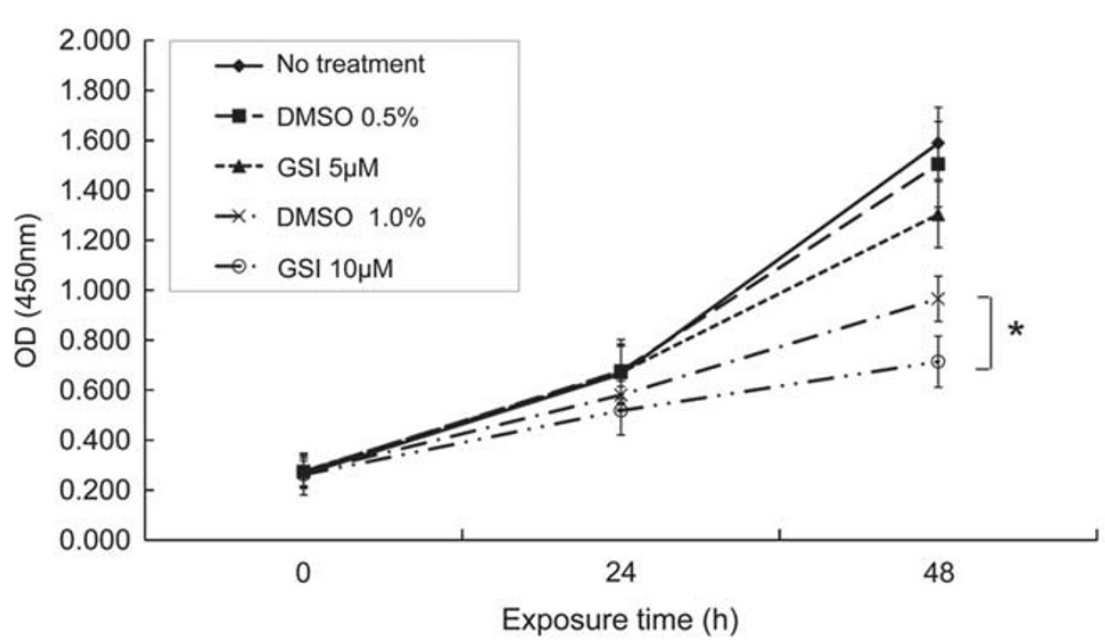

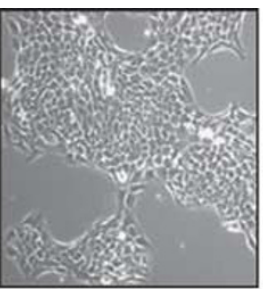

No treatment

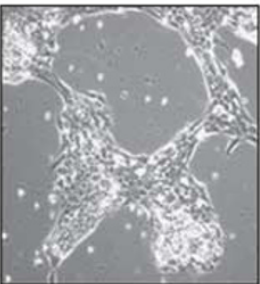

GSI b

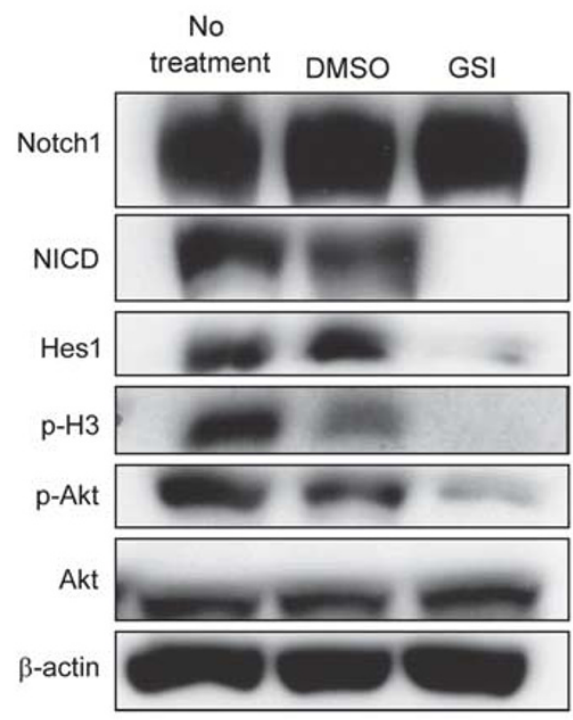

C

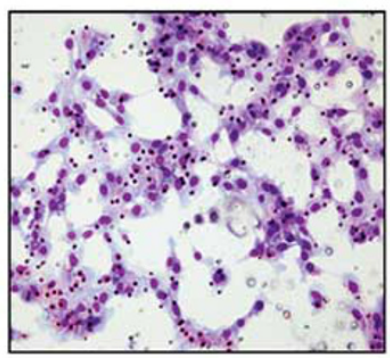

TNF- $\alpha+$ DMSO

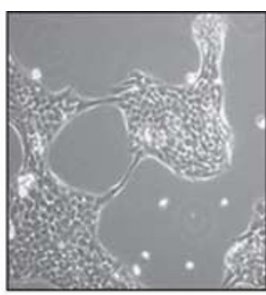

DMSO

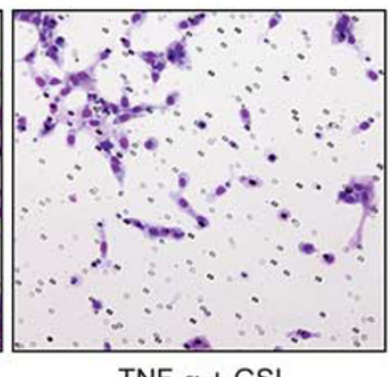

TNF- $\alpha+$ GSI

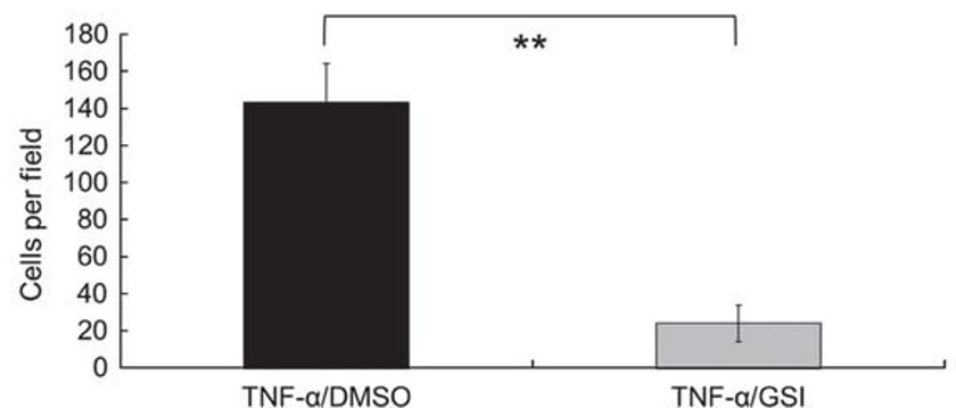

Figure 7 Effects of $\gamma$-secretase inhibitor (GSI) on proliferation, and invasion of SAS cells. (a) SAS cells were incubated with various concentration of GSI or dimethyl sulfoxide (DMSO) for the indicated periods and then examined for viability via a WST assay. GSI significantly inhibited cell proliferation in a dose-dependent manner. The $Y$ axis shows the changes in absorbance at $450 \mathrm{~nm}$; bars: s.d. of triplicate samples. ${ }^{*} P<0.05$; ${ }^{* *} P<0.01$, analyzed by Student's $t$-test. The photomicrographs show representative images of SAS cells under each condition, as described below. Lysates from SAS cells incubated with $1 \%$ DMSO or $10 \mu \mathrm{M}$ GSI for $48 \mathrm{~h}$ were immunoblotted using antibodies as indicated. Decreased expressions of Notch1 and intracellular Notch domain (NICD), phosphorylated histone $\mathrm{H3}(\mathrm{p}-\mathrm{H} 3)$ and phosphorylated Akt (p-Akt) were confirmed. (b) Western blotting of Notch1 signalingrelated proteins $48 \mathrm{~h}$ after GSI treatment. Note the decreased expressions of Notch1, NICD, p-H3 and phosphorylated AKT (p-AKT) in the GSI-treated cells. The expression of $\beta$-actin was used as an internal control. The experiment was performed in triplicate. Images on microscope of SAS cells under each condition. Original magnification, $\times 100$. (c) The effects of GSI on TNF- $\alpha$-dependent SAS cell invasion. SAS cells were incubated with DMSO or GSI for $24 \mathrm{~h}$ in the presence of TNF- $\alpha$. Cells that penetrated the Matrigel-coated membrane were fixed and stained. The photos are representative fields of invasive cells on the membranes. The numbers of invaded cells obtained in three independent experiments were counted and statistically analyzed. The number of invaded cells enhanced by TNF- $\alpha$ was significantly decreased under the GSI treatment conditions. The bar graphs represent the average numbers of cells on the underside of the membranes. The $Y$ axis shows the numbers of cells invading the underside of the membranes. Mean \pm s.d. of three independent experiments. ${ }^{*} P<0.05 ;{ }^{*} P<0.01$, analyzed by Student's $t$-test. The photos are representative fields of invasive cells on the membranes. Original magnification, $\times 100$. Hes, hairly enhancer of split; OD, optical density.

activity. Although it has also been suggested that downregulation of the Notch1 pathway induces the suppression of cell proliferation in OSCCs, ${ }^{34}$ the mechanisms underlying this phenomenon are not well understood. In our present data, the phosphorylation of Akt was downregulated by the inhibition of Notch signaling, which suggests that the Notch1 
expression affects the proliferation of cultured OSCC cell lines via Akt signaling. In OSCC, Akt signaling has an important role in its progression, ${ }^{41,42}$ and inhibition of Akt signaling suppresses malignant phenotype. ${ }^{43}$

Recently, growing evidence has indicated a relationship between Notch signaling and tumor cell invasion. ${ }^{44,45}$ Our present data demonstrated that the Notch1 expression influences the TNF- $\alpha$-dependent invasiveness of OSCC cells via the transcriptional regulation of Slug and Twist, important regulators of cell invasion. ${ }^{31}$ Several reports have described the significance of Notch signaling for the invasiveness of squamous cell carcinomas, including those of the oral cavity. In these reports, MMPs, the nuclear factor- $\kappa \mathrm{B}$ pathway and micro-RNAs were reported to be associated with increases in invasive phenotypes. ${ }^{46,47}$ Our data support these previous findings and we conclude that Notch1 has a role in a certain type of OSCC invasion. However, we need further investigation to determine what mechanisms underlie the invasiveness of OSCC cells because Notch signaling shows cross-talk with many other pathways and regulates the properties of these pathways based on complicated mechanisms.

GSI prevents the activation of Notch signaling, and several Notch inhibitors have been tested for antitumor effects. ${ }^{48}$ Our present data clearly demonstrated that treatment of OSCC cells with GSI effectively reduces the NICD/Hes1 protein expression and prevents growth in OSCC cell lines, similar to that observed in Notch1 knockdown conditions. In our study, GSI treatment inhibited not only cell proliferation but also OSCC cell migration and invasion. Similar effects of GSI on the migration and invasion of cancer cells has been reported in pancreatic cancer and melanoma. ${ }^{49,50}$ These findings suggest that GSI effectively inhibits the Notch pathway in OSCC cell lines and that the progression of OSCC is regulated by this signaling system. Recently, another effect of GSI on the drug resistance phenotype of cancer cells in Notch signaling was reported. ${ }^{51,52}$ Therefore, further study is required to determine the biological significance and antitumor effects of GSI in OSCC.

In conclusion, we demonstrated that the Notch1 expression is involved in the maintenance of the proliferation and TNF- $\alpha$-dependent invasiveness of OSCC cells. Although the use of a single cell line in functional analysis is a limitation of this study, the expressions of NICD, which indicates activation of Notch signaling, in majority of OSCC cell lines and OSCC specimens were confirmed. Moreover, positive correlation between the expressions of Notch1 and NICD was observed in immunohistochemical analysis. Therefore, the activation of Notch signaling may occur in the other cell lines and clinical OSCC. Indeed, one report has demonstrated the tumor suppressor functions of Notch signaling based on the findings of loss-of-function mutations of Notch1 in HNSCC. ${ }^{53}$ However, in that report, this type of mutation was detected in a certain subset of patients having HNSCC. Therefore, considering the previous studies of HNSCCs, ${ }^{34,46}$ including OSCC that indicate the oncogenic functions of
Notch1 and the context dependency of Notch signaling, certain types of OSCC cells may require Notch1 expression for progression. Moreover, GSI, a pharmacological agent known to effectively block Notch1 activation, was found to inhibit the proliferation, migration and invasiveness of OSCC cells, which suggests the potential for using GSI in OSCC treatment.

Supplementary Information accompanies the paper on the Laboratory Investigation website (http://www.laboratoryinvestigation.org)

\section{ACKNOWLEDGEMENTS}

We thank Mr Shinji Kudo, Mrs Motoko Kagayama, Mrs Takako Maeda and Mrs Hiroko Kouzuma for their skillful technical assistance. This study was partly supported by a Grant-in-Aid for Scientific Research (C; No. 21590440) from Ministry of Education, Culture, Sports, Science and Technology of Japan.

\section{DISCLOSURE/CONFLICT OF INTEREST}

The authors declare no conflict of interest.

1. Siegel R, Naishadham D, Jemal A. Cancer statistics, 2012. CA Cancer J Clin 2012;62:10-29.

2. Gupta S, Kong W, Peng Y, et al. Temporal trends in the incidence and survival of cancers of the upper aerodigestive tract in Ontario and the United States. Int J Cancer 2009;125:2159-2165.

3. Napier SS, Speight PM. Natural history of potentially malignant oral lesions and conditions: an overview of the literature. J Oral Pathol Med 2008:37:1-10.

4. Barnes L, Eveson JW, Reichart P, et al. Pathology and Genetics of Head and Neck Tumours. IARC Press: Lyon, 2005, pp 177-180.

5. Warnakulasuriya S. Histological grading of oral epithelial dysplasia: revisited. J Pathol 2001;194:294-297.

6. Artavanis-Tsakonas S, Rand MD, Lake RJ. Notch signaling: cell fate control and signal integration in development. Science 1999;284: 770-776.

7. Gray GE, Mann RS, Mitsiadis E, et al. Human ligands of the Notch receptor. Am J Pathol 1999;154:785-794.

8. Wu L, Sun T, Kobayashi K, et al. Identification of a family of mastermind-like transcriptional coactivators for mammalian notch receptors. Mol Cell Biol 2002;22:7688-7700.

9. Ellisen LW, Bird J, West DC, et al. TAN-1, the human homolog of the Drosophila notch gene, is broken by chromosomal translocations in T lymphoblastic neoplasms. Cell 1991;66:649-661.

10. Puente XS, Pinyol M, Quesada V, et al. Whole-genome sequencing identifies recurrent mutations in chronic lymphocytic leukaemia. Nature 2011;475:101-105.

11. Westhoff B, Colaluca IN, D'Ario G, et al. Alterations of the Notch pathway in lung cancer. Proc Natl Acad Sci USA 2009;106:22293-22298.

12. Weijzen S, Rizzo P, Braid M, et al. Activation of Notch-1 signaling maintains the neoplastic phenotype in human Ras-transformed cells. Nat Med 2002;8:979-986.

13. Miyamoto $Y$, Maitra A, Ghosh B, et al. Notch mediates TGF alphainduced changes in epithelial differentiation during pancreatic tumorigenesis. Cancer Cell 2003;3:565-576.

14. Zayzafoon M, Abdulkadir SA, McDonald JM. Notch signaling and ERK activation are important for the osteomimetic properties of prostate cancer bone metastatic cell lines. J Biol Chem 2004;279:3662-3670.

15. Santagata S, Demichelis F, Riva A, et al. JAGGED1 expression is associated with prostate cancer metastasis and recurrence. Cancer Res 2004;64:6854-6857.

16. Reedijk M, Odorcic S, Chang $L$, et al. High-level coexpression of JAG1 and NOTCH1 is observed in human breast cancer and is associated with poor overall survival. Cancer Res 2005;65:8530-8537.

17. Klinakis A, Lobry C, Abdel-Wahab O, et al. A novel tumour-suppressor function for the Notch pathway in myeloid leukaemia. Nature $2011 ; 473: 230-233$ 
18. Viatour $P$, Ehmer $U$, Saddic $L A$, et al. Notch signaling inhibits hepatocellular carcinoma following inactivation of the RB pathway. J Exp Med 2011:208:1963-1976.

19. Hanlon L, Avila JL, Demarest RM, et al. Notch1 functions as a tumor suppressor in a model of K-ras-induced pancreatic ductal adenocarcinoma. Cancer Res 2010;70:4280-4286.

20. Nicolas $\mathrm{M}$, Wolfer A, Raj $\mathrm{K}$, et al. Notch1 functions as a tumor suppressor in mouse skin. Nat Genet 2003;33:416-421.

21. Ha PK, Benoit NE, Yochem R, et al. A transcriptional progression model for head and neck cancer. Clin Cancer Res 2003;9: 3058-3064.

22. Snijders AM, Schmidt BL, Fridlyand J, et al. Rare amplicons implicate frequent deregulation of cell fate specification pathways in ora squamous cell carcinoma. Oncogene 2005;24:4232-4242.

23. Duan $\mathrm{L}$, Yao J, Wu X, et al. Growth suppression induced by Notch1 activation involves Wnt-beta-catenin down-regulation in human tongue carcinoma cells. Biol Cell 2006;98:479-490.

24. Sakamoto K, Fujii T, Kawachi H, et al. Reduction of NOTCH1 expression pertains to maturation abnormalities of keratinocytes in squamous neoplasms. Lab Invest 2012;92:688-702.

25. Tanaka T, Kohno H, Sakata K, et al. Modifying effects of dietary capsaicin and rotenone on 4-nitroquinoline 1-oxide-induced rat tongue carcinogenesis. Carcinogenesis 2002;23:1361-1367.

26. Ito T, Udaka N, Yazawa T, et al. Basic helix-loop-helix transcription factors regulate the neuroendocrine differentiation of fetal mouse pulmonary epithelium. Development 2000;127:3913-3921.

27. Yamamoto $T$, Kimura $T$, Ueta $E$, et al. Characteristic cytokine generation patterns in cancer cells and infiltrating lymphocytes in oral squamous cell carcinomas and the influence of chemoradiation combined with immunotherapy on these patterns. Oncology 2003;64: 407-415.

28. Delwig A, Rand MD. Kuz and TACE can activate Notch independent of ligand. Cell Mol Life Sci 2008;65:2232-2243.

29. Bozkulak EC, Weinmaster G. Selective use of ADAM10 and ADAM17 in activation of Notch1 signaling. Mol Cell Biol 2009;29: 5679-5695.

30. Ando K, Kanazawa S, Tetsuka T, et al. Induction of Notch signaling by tumor necrosis factor in rheumatoid synovial fibroblasts. Oncogene 2003;22:7796-7803.

31. Weinberg RA. Twisted epithelial-mesenchymal transition blocks senescence. Nat Cell Biol 2008;10:1021-1023.

32. Robbins J, Blondel BJ, Gallahan D, et al. Mouse mammary tumor gene int-3: a member of the notch gene family transforms mammary epithelial cells. J Virol 1992;66:2594-2599.

33. Sriuranpong $\mathrm{V}$, Borges MW, Ravi RK, et al. Notch signaling induces cell cycle arrest in small cell lung cancer cells. Cancer Res 2001;61: 3200-3205.

34. Hijioka $\mathrm{H}$, Setoguchi $\mathrm{T}$, Miyawaki $\mathrm{A}$, et al. Upregulation of Notch pathway molecules in oral squamous cell carcinoma. Int J Oncol 2010;36:817-822

35. Zhang TH, Liu HC, Zhu LJ, et al. Activation of Notch signaling in human tongue carcinoma. J Oral Pathol Med 2010;40:37-45.

36. Gu F, Ma Y, Zhang Z, et al. Expression of Stat3 and Notch1 is associated with cisplatin resistance in head and neck squamous cell carcinoma. Oncol Rep 2010;23:671-676.
37. Joo $\mathrm{YH}$, Jung $\mathrm{CK}$, Kim MS, et al. Relationship between vascular endothelial growth factor and Notch1 expression and lymphatic metastasis in tongue cancer. Otolaryngol Head Neck Surg 2009;140: 512-518.

38. Ling $H$, Sylvestre JR, Jolicoeur P. Notch1-induced mammary tumor development is cyclin D1-dependent and correlates with expansion of pre-malignant multipotent duct-limited progenitors. Oncogene 2010;29:4543-4554.

39. Sikandar SS, Pate KT, Anderson S, et al. NOTCH signaling is required for formation and self-renewal of tumor-initiating cells and for repression of secretory cell differentiation in colon cancer. Cancer Res 2010; 70:1469-1478.

40. Wang Z, Li Y, Ahmad A, et al. Down-regulation of Notch-1 is associated with Akt and FoxM1 in inducing cell growth inhibition and apoptosis in prostate cancer cells. J Cell Biochem 2010;112:78-88.

41. Shinriki $\mathrm{S}$, Jono $\mathrm{H}$, Ueda $\mathrm{M}$, et al. Interleukin-6 signalling regulates vascular endothelial growth factor-C synthesis and lymphangiogenesis in human oral squamous cell carcinoma. J Pathol 2011;225: $142-150$

42. Iamaroon A, Krisanaprakornkit S. Overexpression and activation of Akt2 protein in oral squamous cell carcinoma. Oral Oncol 2009;45: e175-e179.

43. Hong KO, Kim JH, Hong JS, et al. Inhibition of Akt activity induces the mesenchymal-to-epithelial reverting transition with restoring E-cadherin expression in $\mathrm{KB}$ and $\mathrm{KOSCC}-25 \mathrm{~B}$ oral squamous cell carcinoma cells. J Exp Clin Cancer Res 2009;28:28.

44. Wang $Z$, Li Y, Kong $D$, et al. The role of Notch signaling pathway in epithelial-mesenchymal transition (EMT) during development and tumor aggressiveness. Curr Drug Targets 2010;11:745-751.

45. Huber MA, Kraut N, Beug H. Molecular requirements for epithelialmesenchymal transition during tumor progression. Curr Opin Cell Biol 2005; 17:548-558.

46. Liao S, Xia J, Chen $Z$, et al. Inhibitory effect of curcumin on oral carcinoma CAL-27 cells via suppression of Notch-1 and NF-kappaB signaling pathways. J Cell Biochem 2011;112:1055-1065.

47. Subramaniam D, Ponnurangam S, Ramamoorthy $\mathrm{P}$, et al. Curcumin induces cell death in esophageal cancer cells through modulating Notch signaling. PLoS One 2012;7:e30590.

48. Shih leM, Wang TL. Notch signaling, gamma-secretase inhibitors, and cancer therapy. Cancer Res 2007;67:1879-1882.

49. Plentz R, Park JS, Rhim AD, et al. Inhibition of gamma-secretase activity inhibits tumor progression in a mouse model of pancreatic ductal adenocarcinoma. Gastroenterology 2009;136:1741-1749, e1746.

50. Asnaghi L, Ebrahimi KB, Schreck KC, et al. Notch signaling promotes growth and invasion in uveal melanoma. Clin Cancer Res 2012;18: 654-665.

51. Rizzo P, Miao H, D'Souza G, et al. Cross-talk between notch and the estrogen receptor in breast cancer suggests novel therapeutic approaches. Cancer Res 2008;68:5226-5235.

52. Nefedova Y, Sullivan DM, Bolick SC, et al. Inhibition of Notch signaling induces apoptosis of myeloma cells and enhances sensitivity to chemotherapy. Blood 2008;111:2220-2229.

53. Agrawal N, Frederick MJ, Pickering $\mathrm{CR}$, et al. Exome sequencing of head and neck squamous cell carcinoma reveals inactivating mutations in NOTCH1. Science 2011:333:1154-1157. 